\title{
ASSESSING RISK OF THE NATURAL REGENERATION OF INTRODUCED CONIFERS, OR WILDING SPREAD
}

\author{
N.J. LEDGARD
}

\author{
Scion, PO Box 29237, Fendalton, Christchurch, New Zealand \\ Corresponding author: nick.ledgard@scionresearch.com
}

\begin{abstract}
Two decision support systems (DSS) have been developed to assess (a) the threat of introduced conifer (wilding) spread from new plantings and (b) the risk of wildings establishing at any particular site. Scores $(0-4)$ are given for risk factors related to the species involved, their spreading vigour (includes seedling growth rate, age of coning, seed production and seed weight), palatability, siting of the parent seed trees, and vegetation cover and land use, particularly downwind of the seed source. The maximum possible score is 20 , and scores above 12 (DSSa) and 14 (DSSb) indicate high levels of risk. The two DSSs can be used by land managers to quickly assess the likely risk of wilding spread, and to test how they might lower the risk by changing input factors. In this way, spread risk can be mitigated or avoided by good decision-making prior to unwanted wilding spread occurring. Keywords: conifer, natural regeneration, wilding tree, risk, assessment.
\end{abstract}

\section{INTRODUCTION}

The natural regeneration of introduced conifers, or wilding spread, has been occurring in New Zealand for over 100 years (Smith 1903), but has received increasing attention during the last decade (Hill et al.2004). Land management and administrating agencies, such as regional and district councils and the Department of Conservation, now proactively address wilding tree risk and control in their planning, policies and prioritisation of field operations (Bowman 2004; Department of Conservation 2001; Woods 2004). As with the management of any weed or pest, good prevention can save significant funds having to be spent on control. Fortunately, the process of wilding spread is predictable (Ledgard \& Langer 1999), which makes prevention easier than for many other pest plants. A DSS for assessing the risk of spread from new plantings was first produced in 1993 (Ledgard 1994). This paper introduces an updated version of this DSS (referred to as DSSa) and a new wilding DSS (DSSb) for assessing the spread risk onto any site.

\section{THE RISK ASSESSMENT FORMS}

In 1991 the Canterbury Regional Council formed a Wilding Tree Advisory Committee, a major aim of which was to minimise the risk of wilding spread from existing and new stands of conifers. The committee was seeking an easy to use (farmer-friendly) means of assessing spread risk from conifer plantings and to this end approved an early version of DSSa (Ledgard 1994), which has since been used widely by land managers such as regional and district councils. It is designed for use by the owners of conifer stands and only considers the risk of wilding spread from their trees onto all land which is 'associated' with those specific trees. The aim is to help tree owners to make decisions about how they might reduce the risk of becoming a source of wilding trees. In this paper an updated version of DSSa is presented. It has had three new species added, maritime pine (Pinus pinaster), mountain pine (P. uncinata) and dwarf mountain pine (P. mugo), and has been modified slightly to make it easier to follow (see Appendix 1). It is available in electronic form on the Project website (www.wildingconifers.org.nz).

$\mathrm{DSSb}$ is designed for land owners and managers, such as the Department of Conservation (DOC) and the Queen Elizabeth II Trust (QEII), who usually do not own 
the potential source trees, which could be growing anywhere on adjacent properties and over which they may have no control. DSSb allows them to assess any given site's vulnerability to conifer seeds arriving and wildings establishing. It uses the same assessment criteria as DSSa, but these have had to be amended and reordered to accommodate the perspective of the seed-recipient land. DSSb has been field tested by ECan and QEII staff and appears to be useful for estimating a site's vulnerability to wilding invasion (see Appendix 2).

\section{DISCUSSION}

Both DSSa and DSSb address all the major factors influencing wilding spread and establishment, and these have been well addressed previously (Ledgard \& Langer 1999; Ledgard 2004). This paper describes how the factors have been utilised in updating DSSa and developing DSSb. The risk of spread is assessed by supplying information under three categories - the conifer species involved, the siting or location of those species, and the vegetation of the surrounding land together with its use.

\section{Species}

The first two points of both DSSa and DSSb relate to the species involved - their spreading vigour and palatability. Spreading vigour combines knowledge of seedling vigour and growth rate, age of coning, and seed production and weight. For example, the most vigorous spreading species, contorta pine (Pinus contorta), grows fast as a seedling and can produce light-weight seed in quantity before age 10 (Miller \& Ecroyd 1987). In the same category is Douglas-fir (Pseudotsuga menziesii). It is also a fast grower, and although it seeds later (age 10-15) than contorta pine, it can produce large numbers of light-weight seed (Ledgard 2006a). Seed dissemination is aided by the cones hanging free at the ends of branches, from where seed can be readily picked up by wind. Scots pine ( $P$. sylvestris) has not been planted widely, so less is known about its spreading capability, but it produces light seed at a relatively early age, and as it has shown considerable spread potential in the few places where it is found (e.g. Molesworth station, N.J. Ledgard, unpublished data), it has been included in the same 'most vigorous' spreading category as contorta pine and Douglas-fir. Mountain pine, dwarf mountain pine and Corsican pine (P. nigra) are in the second highest category of spreading vigour. The mountain pines can produce light seed at an early age (age 8-10 years; Ledgard \& Ecroyd 1988), but their short compact habit (especially dwarf mountain pine) means that wind is less able to reach the cones and the seed is less readily dispersed over long distances by wind. Corsican pine is not such an early and prolific seed producer as the mountain pines and is a shy coner above $800 \mathrm{~m}$ asl, but it is the least palatable of the common conifers (Crozier \& Ledgard 1990), and hence best adapted to establish where animal browsing might eliminate other species. Species with larger seed (ponderosa, muricata, maritime and radiata pine - P. ponderosa, P. muricata, P. pinaster and P. radiata respectively) are less likely to have seed dispersed long distances (Ledgard 2004), and tend to be more attractive to browsing animals (Crozier \& Ledgard 1990). European larch (Larix decidua) produces light seed (Miller \& Knowles 1988) and can spread long distances, but seed production drops off considerably with increasing rainfall and altitude, and viability can often be low.

The uneven representation of the above species in the high country means that knowledge of altitudinal limits of growth and seeding capability is incomplete, but both contorta and mountain pine can grow and seed well above native treeline (Ledgard 2001; Ledgard \& Baker 1988), and there is good evidence that Scots pine and Douglas-fir can establish from seed at least up to native treeline (N.J. Ledgard, unpublished data). This ability to grow, and possibly produce seed, at higher altitudes than other conifers, is further reason for their higher scoring in the 'spreading vigour' category.

Other conifers named in the two DSSs are the cypresses, spruces and cedars. All are common conifers, often associated with farm plantings. A few wildings can be found in certain sites, but in general natural regeneration is uncommon. For this reason, both DSSs indicate a very low risk of significant spread from these species.

\section{Siting of seed source}

The middle point (criteria 3 in DSSa and 2-4 in DSSb) of both DSSs relates to siting of the parent seed-producing trees. Sites on the more exposed ridges and slopes (often 
called take-off sites) are more likely to spread seed long distances and over large areas. Knowledge of local weather is important in order to supply useful information relative to wind prevalence and strength. Even when this is known, seed can still be dispersed 'upwind' in open areas, especially in hilly and mountainous terrain where greater turbulence is likely. However, due to the orientation of New Zealand across the 'roaring forties' this happens infrequently, and rarely is seed carried more than a few hundred meters against the prevailing wind direction.

\section{Vegetation cover and land use}

The last points (criteria 4-5 in DSSa and 5-6 in DSSb) relate to vegetation and land use, particularly in the area downwind of the seed source. Wilding establishment is markedly influenced by existing vegetation cover and by the level of grazing and browsing pressure.

If the existing vegetation is vigorous and competitive, then establishment success is considerably reduced (Ledgard 2006b). For example, wildings will not establish successfully in improved pasture (Benecke 1967, Davis et al. 1996) or under a closed canopy forest (Ledgard 2004). Cattaneo (2002) also showed that contorta pine established best where there was little vegetation cover.

Browsing by introduced and wild animals is probably the major influence on the survival of young seedlings in the high country (Ledgard 2008). Benecke (1967), working at Tara Hills, demonstrated the effect of different levels of browsing pressure by sheep, showing that a sheep stocking level as low as 0.5 stock units/ha was enough to significantly depress contorta pine seedling survival. More recently, Cattaneo (2002) had the same results on Flock Hill station. In a simulated browsing trial, Crozier \& Ledgard (1990) found that seedlings could be readily killed by removal of all green foliage before age 2 - after which time shoots had become sufficiently woody and robust to make it much harder for browsing animals to remove all needles and hence ensure mortality. Davis et al. (1996) looked at the effect of excluding rabbits, birds and insects from young radiata pine seedlings during their first year of growth from seed. Rabbits were clearly the major cause of seedling failure. Where rabbit numbers have been significantly reduced, such as after the arrival of the rabbit haemorrhagic disease in the late 1990s, all woody seedlings, including wildings, have a much greater chance of survival.

The above research results have been combined with considerable field experience to produce the DSS assessment forms, which are simple and allow land managers to estimate the risk of tree spread even if they have no prior knowledge on the topic. DSSa is based on the original prototype (Ledgard 1994), which has been improved by incorporating recent research and experience. DSSb, the form for assessing risk into new areas (Appendix 2), has not been published before. It should be noted that in this form, a score of zero for any one factor can mean a very low spread risk, even if scores for the other factors are high. For example, there is little likelihood of wilding spread from a very spread-prone species in an exposed windy site, if it is surrounded by intensively grazed pasture.

In conclusion, the two assessment forms can be used by land managers to quickly undertake an assessment of likely risk of wilding spread. Depending on the resulting score, managers can do a sensitivity analysis, i.e. test how they might lower the risk of spread by changing factors such as siting of new plantings or the use of surrounding land. In this way, spread risk can be mitigated or avoided by good decision making prior to planting (DSSa), or prior to the time when wildings are likely to arrive and possibly become a problem on a new site (DSSb).

\section{ACKNOWLEDGEMENTS}

The author is grateful to Lisa Langer for assistance with the initial development of DSSa, and to Miles Giller (QEII Trust) and staff of Environment Canterbury for assistance with the development and field testing of DSSb.

\section{REFERENCES}

Benecke U 1967. The weed potential of lodgepole pine. Review 13, Journal of the New Zealand Mountain Lands Institute, Lincoln University, Canterbury, New Zealand. Pp. 36-43. 
Bowman RG 2004. Responsibilities of local government in wilding control management. In: Hill, RL, Zydenbos SM, Bezar CM ed. Managing wilding conifers in New Zealand - present and future. New Zealand Plant Protection Society, Christchurch, New Zealand [ISBN 0-478-10842-7]. Pp. 45-53.

Cattaneo M 2002. Effects of microsite characteristics, competition and grazing on Pinus contorta and Pseudotsuga menziesii seedling estalishment. M.Sc. thesis, School of Forestry, University of Canterbury. $154 \mathrm{pp}$.

Crozier ER, Ledgard NJ 1990. Palatability of wilding conifers and control by simulated sheep browsing. In: Bassett C, Whitehouse LJ, Zabkievicz JA ed. Alternatives to the chemical control of weeds. Proceedings of International Conference, Forest Research Institute, Rotorua, New Zealand, 25-27 July 1989. Forest Research Institute Bulletin No. 155. Pp. 139-143.

Davis MR, Grace LJ, Horrell RF 1996. Conifer establishment in the South Island high country: influence of mycorrhizal inoculation, competition removal, fertiliser application, and animal exclusion during seedling establishment. New Zealand Journal of Forest Science (3): 380-394.

Hill, RL, Zydenbos SM, Bezar CM ed. 2004. Managing wilding conifers in New Zealand - present and future. New Zealand Plant Protection Society, Christchurch, New Zealand [ISBN 0-478-10842-7]. $126 \mathrm{pp}$.

Ledgard NJ, Ecroyd CE 1988. Introduced forest trees in New Zealand: recognition, role and seed source. 4. Pinus mugo Turra - dwarf mountain pine; Pinus uncinata Mirbel - mountain pine. Forest Research Institute Bulletin No. 124, P.O. Box 3020 , Rotorua, New Zealand. 10 pp.

Ledgard NJ 1994. A form for assessing the risk of conifer spread in the South Island high country. New Zealand Forestry 39 (1): 26-27.

Ledgard NJ, Langer ER 1999. Wilding prevention - guidelines for minimising the risk of unwanted spread from new plantings of introduced conifers. Forest Research, Box 29237, Fendalton, Christchurch. 21 pp.

Ledgard NJ 2001. The spread of Lodgepole pine (Pinus contorta, Dougl.) in New Zealand. Journal of Forest Ecology and Management 141: 43-57.

Ledgard NJ 2004. Wilding conifers - New Zealand history and research background. In: Hill, RL, Zydenbos SM, Bezar CM ed. Managing wilding conifers in New Zealand - present and future.. New Zealand Plant Protection Society, Christchurch, New Zealand [ISBN 0-478-10842-7]. Pp. 1-25.

Ledgard NJ 2006a. Determining the effect of increasing vegetation competition through fertiliser use on the establishment of wildings in unimproved high country grassland. New Zealand Journal of Forestry 51(3): 29-34.

Ledgard NJ 2006b. Douglas-fir wilding spread and mitigation of risk. New Zealand Douglas-fir Research Cooperative Report No 50.25 pp.

Ledgard NJ, Baker GC 1988. Mountainland forestry - 30 year's research in the Craigieburn Range, New Zealand. New Zealand Forest Research Institute Bulletin No $146.64 \mathrm{pp}$.

Ledgard N, Norton D 2008. The impact of browsing on wilding conifers in the South Island high country. New Zealand Journal of Forestry 52(4): 29-34.

Miller JT, Ecroyd CE 1987. Introduced forest trees in New Zealand: recognition, role and seed source. 1. Pinus contorta Loudon - contorta pine. Forest Research Institute Bulletin No. 124, P.O. Box 3020, Rotorua, New Zealand. 12 pp.

Miller JT, Knowles FB 1988. Introduced forest trees in New Zealand: recognition, role and seed source. 3. The larches. Larix decidua Miller; Larix kaemferi (Lambert) Carr., Larix x eurolepis A. Henry. Forest Research Institute Bulletin No. 124, P.O. Box 3020, Rotorua, New Zealand. 17 pp.

Smith WW 1903. Plants naturalised in the county of Ashburton. Transactions of the Proceedings of the New Zealand Institute 36. Pp. 203-225.

Woods DC 2004. The highs and lows of conifer control operations: the good, the bad and the ugly. In: Hill, RL, Zydenbos SM, Bezar CM ed. Managing wilding conifers in New Zealand - present and future. New Zealand Plant Protection Society, Christchurch, New Zealand [ISBN 0-478-10842-7]. Pp. 55-63. 


\section{Appendix 1 (DSSa). \\ CALCULATING WILDING SPREAD RISK FROM NEW PLANTINGS}

(Enter appropriate score for all five questions)

\section{Species - spreading vigour}

$>$ Cypresses (Cupressus spp), cedars (Cedrus spp), spruces (Picea spp) - see NOTES below

$>$ Radiata $(P$. radiata $)$ and muricata $(P$. muricata $)$ pine

$>$ Ponderosa (P. ponderosa), maritime (P. pinaster) pine, European larch (Larix decidua)

$>$ Corsican $(P$. nigra $)$ and mountain/dwarf mountain $(P$. uncinata/mugo) pine

$>$ Douglas-fir (Ps. menziesii), Scots (P. sylvestris), Lodgepole/contorta (P. contorta) pine

\section{Species - palatability}

Enter score (1,2,3 or 4) here

$>$ Radiata, maritime and ponderosa pine

$>$ Lodgepole and muricata pine and European larch

$>$ Scots and mountain/dwarf mountain pine and Douglas-fir

$>$ Corsican pine

\section{Siting}

Enter score (1,2,3 or 4) here

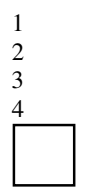

Either sheltered sites, or slopes facing away from strong / prevalent winds

$>$ Sites partially exposed to strong / prevalent winds (often from N \& W $-200^{\circ}$ to $45^{\circ}$ )

$>$ Sites fully exposed to strong / prevalent winds

$>$ Either 'take-off' site - i.e. ridgetops, on or at base of slopes $\left(>10^{\circ}\right)$

or undulating land fully exposed to strong/prevalent winds

\section{Downwind landuse - within $200 \mathrm{~m}$}

Enter score (1,2,3 or 4) here

$>$ Either developed pasture/regular mob stocking (sheep) or closed canopy scrub/forest

$>$ Semi improved (some fertiliser use in past) sheep grazing/occasional mob stocking

$>$ Extensive grazing only

$>$ No grazing

\section{Downwind landuse - from $200 \mathrm{~m}-400 \mathrm{~m}$ (if 1 or 2 scored in 'Siting')} or from $200 \mathrm{~m}-2 \mathrm{~km}$ (if 3 or 4 scored in 'Siting')

$>$ Either developed pasture/regular mob stocking (sheep) or closed canopy scrub/forest

$>$ Semi improved grazing/occasional mob stocking

$>$ Extensive grazing only

$>$ No grazing

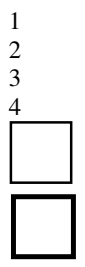

\section{TOTAL SCORE}

\section{NOTES:}

A score of 12 or more means a high spread risk.

A high risk does not necessarily mean that trees should not be planted. A change of species, or siting, or downwind land management can significantly lower spread risk. Or a commitment to wilding removal can be made this is not onerous, particularly with regard to long distance spread from plantings on flat land (in 3 - scores $1,2$ or 3$)$.

Cypresses, cedars and spruces - a high spread risk is very unlikely with species from these genera.

Long distance spread. This is likely if a score of 3 or 4 in 'Siting' (in 3) is followed by a 3 or 4 in 'Downwind landuse' (in 5), especially if larch, Douglas-fir, or Corsican, contorta, mountain or Scots pines are involved. 


\section{Appendix 2 (DSSb). CALCULATING RISK OF WILDING TREE SPREAD INTO/WITHIN NEW SITES Select score applicable for each category)}

1). SPECIES PROVIDING SEED SOURCE choose one species only) Spreading vigour varies with species:

$>$ Cypresses, spruces and cedars

$>$ Radiata (P. radiata) and ponderosa (P. ponderosa)

$>$ Muricata (P. muricata) and maritime (P. pinaster) pine and larches (Larix spp)

$>$ Corsican $(P$. nigra $)$ and mountain/dwarf mountain (P. uncinata/mugo) pine

$>$ Douglas-fir (Ps. menziesii), Scots (P. sylvestris) and Lodgepole/contorta (P. contorta) pine

\section{2). SITING OF SOURCE TREES *}

\section{Source trees are on ...}

$>$ Sites well sheltered from prevalent and strong winds

$>$ Flat sites $\left(10^{\circ}\right)$, partially exposed to strong/prevalent winds

$>$ Lea slopes where strong eddy gusts are likely

Dlat sites $\left(10^{\circ}\right)$, fully exposed to strong/prevalent winds

$>$ Either elevated 'take-off' sites, (ridge-tops, or base of exposed slopes $>10^{\circ}$ ) or undulating land, fully exposed to strong/prevalent winds

\section{3). SITING OF SAMPLE SITE RELATIVE TO SOURCE TREES}

\section{Location relative to seed-dispersing winds}

$>\mathrm{Up}$-wind relative to prevalent or strong winds (If upwind and $>1 \mathrm{~km}$ distant - score 0)

$>$ Subject to cross-winds and/or wind-eddies relative to prevalent or strong winds

$>$ Down-wind relative to prevalent and strong winds (often from North and West)

\section{4). DISTANCE OF SAMPLE SITE FROM SOURCE TREES}

\section{Enter score 0, 1,2 or 3) here}

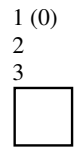

$>$ Greater than $5 \mathrm{~km}$

$>1-5 \mathrm{~km}$

$>200 \mathrm{~m}-1 \mathrm{~km}$

$>0-200 \mathrm{~m}$

Enter score 0, 1, 3 or 4) here

5). VEGETATION OF SAMPLE SITE (if Douglas-fir involved see ** below)

$>$ Either developed pasture; or rank grass; or closed canopy forest/scrub; or tussock/grassland with a continuous, vigorous, permanent vegetation cover

$>$ Either open forest or shrub/tussock/grassland with mostly dense vegetation cover

$>$ Shrubland/tussock/grassland with a moderate vegetation cover

$>$ Either open slips/rockland or shrubland/tussock/grassland with a light vegetation cover

\section{6). GRAZING WITHIN SAMPLE AREA}

\section{Enter score 0, 1, 2 or 3) here}

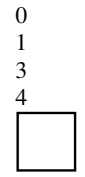

$>$ Developed pasture and/or regular mob stocking with sheep ***

$>$ Semi-improved grazing (sheep/cattle)/occasional mob stocking with sheep

$>$ Extensive grazing only $* * * *$

$>$ No grazing

Enter score 0, 1, 2 or 3) here

See NOTES below for score interpretation) 


\title{
NOTES:
}

* Altitude. The coning ability of some species drops off quickly with increasing altitude. Contorta and mountain pine will establish and cone above native treeline. Scots pine and Douglas-fir will establish at tree line. Corsican pine and Douglas-fir coning drops off quickly above 800 and $1100 \mathrm{~m}$ respectively - the limit for Scots pine coning is unknown. Radiata pine is a reluctant spreader above 600-700 m, except on the warmer sites. The altitudinal establishment and coning limits for muricata pine and larch are unknown.

** Douglas-fir. This species is more shade tolerant than the other common conifers. For this species score 2 for open forest or shrub/tussock/grassland with mostly dense vegetation cover, or 3 for shrubland/tussock/grassland with a moderate vegetation cover.

*** Regular mob stocking. If the pasture is only semi-improved and the seed rain is heavy, such as alongside mature conifers (particularly Corsican pine - the least palatable conifer), regular mob stocking may not prevent wilding establishment over the long term.

**** Light grazing. This will reduce wilding establishment, but given enough time, some wildings will eventually grow to above browse height. Palatability of introduced conifers is (in decreasing order): radiata $>$ ponderosa $>$ contorta $>$ larch $>$ Scots pine $>$ Douglas fir $>$ Corsican pine.

Larger sources of seed are likely to lead to a greater density of seedlings.

\begin{abstract}
ASSESSMENT
A score of $\mathbf{1 4}$ or more indicates a high risk of invasion by the assessed species onto the sample area. But a high risk is unlikely where any one category scores a 'O', especially in (1),( 5) or (6).

A high risk does not necessarily mean that the area will inevitably succumb to wilding trees. A commitment to wilding removal can be made, possibly involving the owner of the source trees. Providing it is timely (before wildings cone and produce seed), this commitment need not necessarily be onerous.
\end{abstract}

